\title{
Evaluation of quality and antioxidant activity of developed instant black tea and commercial tea (Camellia sinensis) available in Bangladesh
}

\author{
Taslima Ahmed, Nazmul Sarwar
}

Chittagong Veterinary and Animal Sciences University, Chittagong, Bangladesh

\section{Keywords:}

Instant tea

Antioxidant

Caffeine

Polyphenol

Tannin

Bangladesh

Article history:

Received 21.10.2018

Received in revised

form 19.11.2018

Accepted 03.12.2018

\section{Corresponding \\ author:}

Nazmul Sarwar

E-mail:

nazmulsarwar@

cvasu.ac.bd

\section{Abstract}

Introduction. The aim of the current study was to develop a novel technique for the production of antioxidantrich instant black tea powder.

Materials and methods. Antioxidant-rich instant black tea was produced by spray drying of the concentrated brew of processed tea leaves with the incorporation of bioactive compounds from fruits and vegetables. The quality of instant tea produced was compared with other commercial instant tea and tea granules.

Results and discussion. Developed instant black tea had good liquoring characteristics, and various constituents were also in the acceptable range. Caffeine content was generally high in all the tea samples and ranged from $2.2 \%$ to $3.1 \%$ in all samples. Total polyphenols content was varied between $17.38 \%$ and $22.67 \%$ and developed instant black tea has higher polyphenols than others. Tannin content ranged from 7.42 to $10.43 \%$ in all samples, while the developed instant black tea had the lowest content such anti-nutrient content than others. Developed instant black tea showed the highest potency of scavenging activity on DPPH radical followed by commercial instant green tea and black tea granules.

Conclusion. Developed instant black tea had higher polyphenol and antioxidant capacity than others Bangladeshi tea which may act as a substitute for natural antioxidants and as a promising agent for beneficial influence in human health.

DOI: $10.24263 / 2310-$

1008-2018-6-2-4 


\section{Introduction}

Tea, Camellia sinensis (L.) O. Kuntze (Theaceae) is the most extensively consumed beverage among the peoples around the world after water (Muktar and Ahmad, 2000). Although, nowadays tea plants are cultivated all across the world, the best growth of them can be seen in the equatorial and sub-tropical sloping lands of the world as they like torrid, humid climate with sufficient rainfall and well-drained, slightly acidic soil (Graham, 1999). The climate, to which the commercially grown tea plants comply, has a great influence on their ecophysiology (Carr, 1972). The tea plants, cultivated for commercial purposes, come from the hybrids of two specific independent ecotypes i.e., the Assam-type (var. assamica) and the China-type (var. sinensis) (Car et al., 1972). Tea is a very popular beverage especially due to its therapeutic property. In a conventional method, young tea leaves and buds of tea plants (Camellia sinensis) are infused in hot boiling water before consumption. The outlook, restorative property, flavor and aroma of tea vary based on different factors like climatic status, topography, production, processing and different hybrids of tea plants. Based on oxidation tea types are black tea (fully oxidized), green tea (not oxidized) and oolong tea (partially oxidized). The factors like origin, age and processing methods vastly influence the chemical constituents of tea leaves. Hot water helps to extract the flavor, pigment and other soluble compounds from the tea leaves. A large portion of dry matter in tea leaves like polyphenol is soluble in hot water.

Caffeine is a naturally synthesized product occurred by the methylation of hypoxanthine or xanthine mostly found in tea, coffee, seeds etc. The chemical formula of caffeine is $\mathrm{C}_{8} \mathrm{H}_{10} \mathrm{~N}_{4} \mathrm{O}_{2}$ and the chemical name is 1,3,7-Trimethylpurine-2,6-dione. It is the methylxanthine alkaloid which can differ widely in structure and reactivity. This is often used as psychoactive/therapeutic drugs. The amount of caffeine varies from food to food like tea, coffee, chocolate etc. Among the dry matters of tea leaves, about 2.5-5.5\% is caffeine which provides the slightly bitter, astringent taste and flavor in tea. Caffeine has different health effects on our body and high doses of caffeine can cause a bad impact on our health. Light consumption of tea can result in short term headache, nausea and anxiety. An overdose of caffeine can lead a person to different diseases like Parkinson's disease, type-2 diabetes, hepatic diseases, and cardiovascular disease etc. Caffeine interferes with the physiological action of adenosine receptors, a class of G-protein, to make a person vigilant. It is a stimulating agent that plays role in our central nervous system, heart etc. It also increases the production of urine (Komes et al., 2009).

Polyphenol is the vital quality indicators of tea which comprises $25-35 \%$ of the dry matters of fresh tea leaves and buds. They are the essential elements providing antioxidant property for which tea leaves are popular. The main classes of polyphenols found in tea are flavonols such as quercetin, myricetin, kaempferol and flavanols or catechins such as (-)epicatechin, (-) - epigallocatechin, (-)-epicatechin-3-gallate and (-)-epigallocatechin-3gallate and also some complex catechins such as theaflavins and thearubigins (Wang et al., 2000; Miean and Mohamed, 2001; Yao et al., 2006). Green tea contains more content of tea polyphenols than oolong and black tea (Bharadwaz and Bhattacharjee, 2012).

Tannins are the bioactive compounds found in tea which are also responsible for the dark color and astringent taste. Tea "tannins" are not similar to the other tannins like tannic acid that are found in other plants. The extracts of tea leaves do not contain any tannic acid (Mohammed and Sulaiman, 2009). However, tannins are responsible for antioxidant activities for which they are considered as beneficial. Anti-oxidant activities of tannins are the main reason behind the anti-carcinogenic and anti-mutagenic properties in tea. Apart from this, they also provide anti-microbial properties that act in opposition to the different group 


\section{- Food Technology -}

of bacteria, fungi and viruses. The nutrition facts of different foods like vegetables, fruits, tea, cocoa, alcoholic and non-alcoholic beverages may immensely depend on the amount of tannin present in those foods. So the presence of tannins in high amounts may decrease the nutritional values in those foods. This effect leads to some unexpected consequences on the utilization of vitamins and minerals, the inhibition of activities of digestive enzyme and Iron absorption, protein precipitation etc. (Lau et al., 1989, Chung et al., 1998; South and Miller, 1998; Khasnabis et al., 2015). And thus, the application of tannins plays important roles in those effects.

Tea has a long history with the human being. From the very beginning, green tea is providing a high amount of biologically active compounds that have been playing a significant role in the human body. The anti-oxidative agents present in the tea leaves play a consequential role in preventing different diseases like cancer and cardiovascular diseases etc. (Luczaj and Skrzydlewska, 2005; Yang, 2002). Around the world, the consumers of black tea are more significant than that of green tea. However recent researches show that efficient consumption of tea can provide advantageous effects on the human body including reduced risk of cardiovascular disease, certain types of cancer, inflammatory bowel, liver and neurodegenerative diseases, diabetes, and weight loss etc. (Dufresne and Farnworth, 2001). These health benefits of green tea are found due to its immense anti-oxidative property. Recently numerous studies proved the extensive area of anti-carcinogenic effects of green tea on the human body (Muzolf and Tyrakowska, 2007).

But in Bangladesh black tea is more popular than green tea among people due to its brightness, briskness, flavor, and color. That's why the need for antioxidant-rich black tea is demanding nowadays. This investigation was carried out with the objectives to develop new process technology for the preparation of antioxidant-rich instant tea and to evaluate its quality by comparison with commercial black tea available in Bangladesh.

\section{Materials and methods}

\section{Collection of samples}

A total of 45 samples belonging to three commercial instant teas $(\mathrm{B}, \mathrm{C}, \mathrm{D})$ and six commercial black tea granule brands $(\mathrm{E}, \mathrm{F}, \mathrm{G}, \mathrm{H}, \mathrm{I}, \mathrm{J})$ were collected from the local market in Bangladesh for analysis within a period of 6 months from 1st January 2018 to 30th June, 2018. Samples were coded to overcome the sampling biasness.

\section{Development of antioxidant-rich instant tea}

For the production of antioxidant-rich instant tea, fresh green leaves were plucked from Kodala Tea Estate, Chittagong, Bangladesh. Young tea (Camellia sinensis) shoots with two leaves and an apical bud was naturally withered for $16 \mathrm{~h}$. The withered leaf was macerated in a laboratory hammer mill. The macerated leaf was subjected to fermentation (i.e. oxidation) under the humid environment $\left(30-32{ }^{\circ} \mathrm{C}, 80-85 \% \mathrm{RH}\right)$ for $80-90 \mathrm{~min}$. The fermented leaf is pressed in a mini hydraulic press at $3234-4312 \mathrm{kPa}$ pressure for $10 \mathrm{~min}$ to expel a part of juice containing soluble solids. Whereas, bioactive-rich fruits and vegetables were collected from the local market in Chittagong city, Bangladesh and washed with water and chopped into small pieces with sharp knives. Then transferred into respective beakers added with absolute ethanol, and left to shake on a shaker for $72 \mathrm{~h}$ at room temperature. The solvent was separated from the residue by straining. The filtrates were collected and stored 
at room temperature while the residues were re-extracted twice, each time with fresh solvent. Finally, all the filtrates were combined and evaporated under reduced pressure at $60^{\circ} \mathrm{C}$ using a rotary evaporator to obtain the crude extracts. The crude extracts $(5 \%)$ were added to tea shoot juice. The juice is then heated for $2 \mathrm{~min}$ in a water bath at $90-100^{\circ} \mathrm{C}$ till the temperature of the juice rises to $60-70^{\circ} \mathrm{C}$ which causes the inactivation of enzymes responsible for the oxidation reactions. The mixture is then subjected to spray drying (Mini Spray Dryer B-290, BÜCHI Labortechnik AG, Switzerland) to obtain instant tea powder and stored at room temperature prior to analysis. The process flow chart for the production of instant black tea is presented in Figure 1.

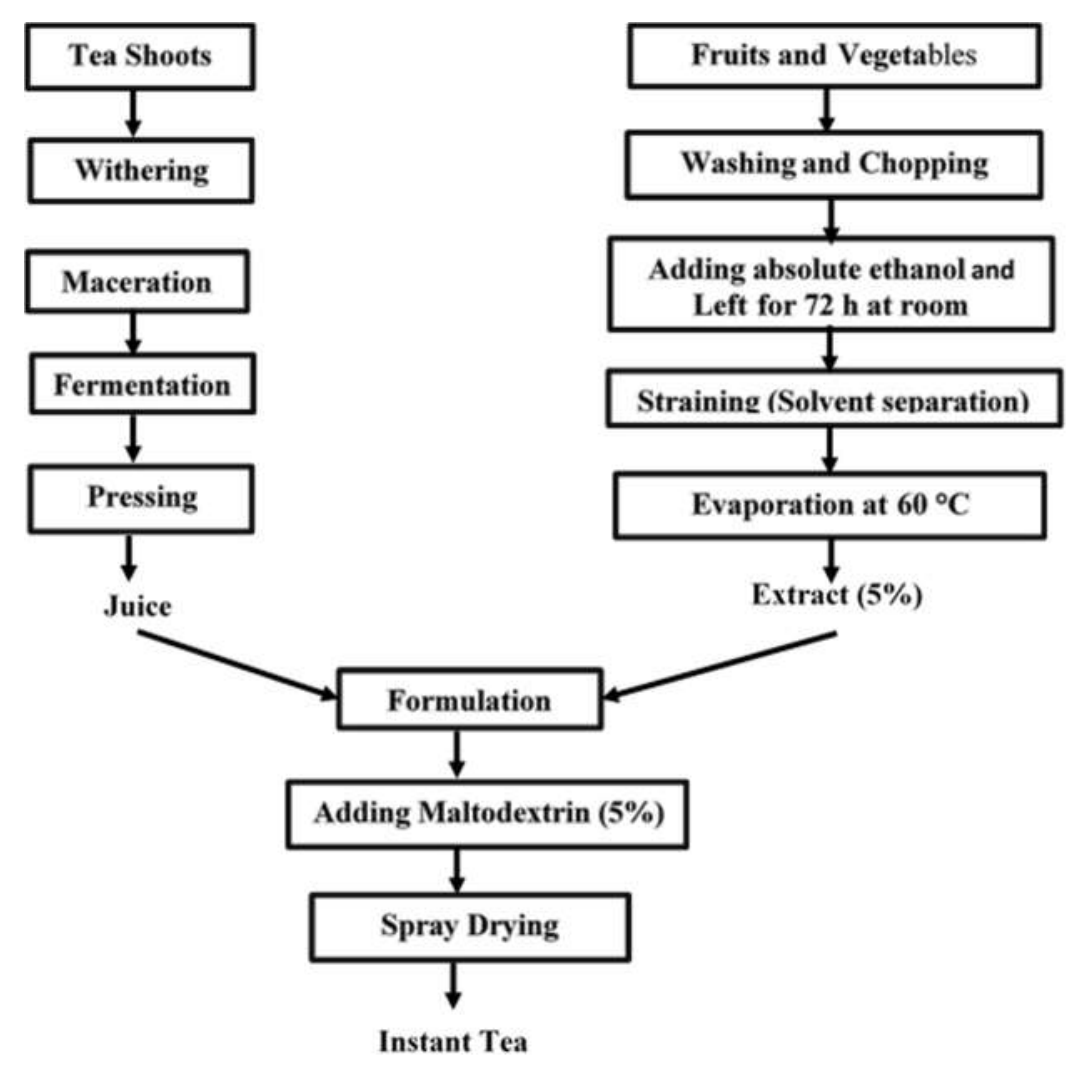

Figure 1. Flowchart of production of antioxidant-rich instant black tea

\section{Sensory evaluation}

A group of panelists conducted the sensory evaluation of the tea according to the method described by Potter (1968). Tea samples were evaluated for the various quality attributes using the standard tea testing procedure. The brew was prepared for each sample by the standard method and assessed for color, flavor, pungency, strength, mouthfeel and overall acceptability by a taste panel. The tea samples were evaluated for degree of liking on the basis of quality attributes of dry leaf, liquor, and infused leaf by using 9-point hedonic scales (Overall scale used: $9=$ like extremely; $8=$ like very much; $7=$ like moderately; $6=$ like slightly; 
$5=$ neither like nor dislike; $4=$ dislike slightly; $3=$ dislike moderately; $2=$ dislike very much; $1=$ dislike extremely) and score 5.0 was considered the borderline of acceptability. Five experienced judges ( 3 males and 2 females; $25-30$ years old) had been involved in the sensory analysis of teas. The sensory evaluation was conducted between 9:30 and 10:30 am and panelist received four samples per session. Sessions were performed in individual partitioned booths and scores among panelists were averaged. The mean sensory score for different quality attributes for various tea samples was determined and statistically analyzed for the variance. The mean sensory score for the quality attributes of various tea samples is given in Table 1.

\section{Extractives determination}

Approximately $2 \mathrm{~g}$ of tea samples were accurately weighed in a tarred flat-bottom dish, dried in the hot air oven for 5 hours at $1000 \mathrm{C}$. After drying, the dish was removed from the oven, cooled and weighted. Dried tea samples were transferred to a round-bottom flask with $100 \mathrm{ml}$ distilled water and reflux for one hour in a laboratory reflux unit. Filtration was carried out into a $250 \mathrm{ml}$ graduated flask and residue with the filter paper returned to the reflux flask, further adding $100 \mathrm{ml}$ distilled water and reflux for an additional hour. Filtered into the volumetric flask, rinsed the reflux flask with hot water and passed the rinsing's through the filter. The filter was washed with hot water until the volumetric flask is filled nearly to the mark. Then cooled, diluted to $250 \mathrm{ml}$, mixed and pipetted $50 \mathrm{ml}$ into a weighed metal evaporating dish. Finally, the solution was evaporated on a rotary evaporator and dried in the oven. Cooled and weighed.

$$
\text { Water-soluble extractives }=\text { Weight of residue } \times \frac{250}{50} \times \frac{100}{\text { weight of dried tea }}
$$

(Manley, 1965; Iwasa et al., 1966).

\section{Caffeine content determination}

The separation process of caffeine from the tea leaves was carried out by following a modified method described by Atomssa and Gholap (2011); Hampp (1996); AOAC (2016). In short, at first $5 \mathrm{~g}$ of tea leaves were taken into a $150 \mathrm{~mL}$ cleaned beaker followed by the addition of $30 \mathrm{~mL}$ of distilled water and $2.0 \mathrm{~g}$ of sodium carbonate. Next, the mixture was constantly boiled for 10 minutes on an electric hot plate. A small flat glass was placed on the beaker to avoid undesirable and exceeding evaporation. The hot tea was separated by using a strainer and placed into a $50 \mathrm{~mL}$ Erlenmeyer flask. The remaining tea leaves were transferred into the beaker followed by addition of $20 \mathrm{~mL}$ of water. Then the previous procedure was repeated again and the $20 \mathrm{~mL}$ of hot tea was transferred into the Erlenmeyer flask. The residual tea leaves were discarded. After that, the hot tea was kept to cool at room temperature and transferred into a $125 \mathrm{~mL}$ separatory funnel that was supported by a ring stand. About $10 \mathrm{~mL}$ of dichloromethane was added followed by the installation of the stopper. Then the separatory funnel was shaken gently in a swirl motion so that no bubble may form. The funnel was frequently vented to relieve the vapor pressure created inside the funnel. After that, the funnel was placed on the ring stand allowing the contents to settle and the stopper was removed. Two individual clear layers were created where the emulsions between the layers were removed by swirling the contents gently with the help of a glass rod. The lower layer containing the dichloromethane was drained out gingerly into a $50 \mathrm{~mL}$ Erlenmeyer flask so that no portion of the aqueous layer may issue. When the emulsion between the layers 


\section{— Food Technology -}

remained, it was also transferred in to the Erlenmeyer flask. Then, another $10 \mathrm{~mL}$ of dichloromethane was added in the separatory funnel and the previous steps were repeated. After that, about half a spoon of anhydrous sodium sulfate was added to the separated dichloromethane extracts and gently shake the Erlenmeyer flask. This sodium sulfate was added to absorb the little water dissolved in the dichloromethane which could not be separated unexpectedly. The sodium sulfate and the water precipitated at the bottom of the flask. Finally, the dichloromethane extract separated into a clean dry beaker and placed on a hot water bath to evaporate the dichloromethane. The remaining caffeine was then weighted and kept in a pre-weighed plastic bag. All the data of the amount of the caffeine were recorded.

Calculation of caffeine percentage:

$$
\% \text { Caffeine }=\frac{W 1 \times 100}{W 2}
$$

$\mathrm{W} 1=$ weight in $\mathrm{g}$ of the evaporation residue, $\mathrm{W} 2=$ weight in $\mathrm{g}$ of tea/coffee used

\section{Total polyphenols content determination}

Total phenolic content (TP) was determined according to a modified method of Bharadwaz and Bhattacharjee (2012). Firstly extraction of polyphenols from dried tea leaves were done. $5 \mathrm{~g}$ of tea leaves were dried and crushed and added to hot water $(60 \mathrm{oC})$ in the ratio $1: 20$ with periodical stirring to deactivate enzymes. Then the filtrate is collected and tea solution is concentrate by using rotavapor (water bath at $60 \mathrm{oC}$ ). Then, decaffeination of tea extract was done by adding an equal volume (about $245 \mathrm{ml}$ ) of $\mathrm{CH} 2 \mathrm{Cl} 2$ to the concentrate and shaken in a separating funnel. The lower part being caffeine (chlorophyll, lipid, carbohydrate etc.) dissolved in $\mathrm{CH} 2 \mathrm{Cl} 2$ and upper part being the undissolved remaining concentrate. Finally, extraction of polyphenols from decaffeinated crude extract was done by mixing $250 \mathrm{ml}$ ethyl acetate and $0.1 \mathrm{~g}$ ascorbic acid (to prevent oxidation) in a separating funnel to the undissolved remaining tea concentrate. The mixture is immiscible, the upper yellow part is polyphenol dissolved in ethyl acetate and the lower part is the remaining tea solution (oil, fats, lipids etc.). The solution is then concentrated and the polyphenols were dried and stored in a desiccator to prevent stickiness. The result was expressed in $\%$ of extracted polyphenols for tea.

\section{Tannin content determination}

Extract preparation. Tea extract was prepared based on the principle of water-soluble property of tannins. At first, $1 \mathrm{~g}$ of tea leaves and $25 \mathrm{~mL}$ of distilled water were taken in a small beaker and placed on a hot plate magnetic stirrer for 5 minutes at $70^{\circ} \mathrm{C}$. Next, the heated liquor was allowed to cool. Then filtration of the tea leaves was done using Whatman no. 1 filter paper. Then, the filtrate was centrifuged at 1000rpm for 15 mins to separate the tea extracts containing water-soluble compounds. After that, the supernatant was brought into a screw-capped tube which was sterilized previously. Finally, the tube was stored at $4^{\circ} \mathrm{C}$ for qualitative and quantitative analysis.

Qualitative analysis of tannin. The presence of tea tannins can be detected by using the ferric chloride test. Tea tannins provide greenish color and precipitation when ferric chloride solution is added to them. According to this principle, $1 \mathrm{~g}$ of tea extract was taken in a test tube followed by the addition of $2-3$ drops of $5 \%(\mathrm{w} / \mathrm{v})$ aqueous ferric chloride solution. The 
reaction between them resulted in greenish precipitation which indicates the presence of tannins in the tea extract.

Quantitative analysis of tannin. The quantity of tannin in the tea extract was estimated by using the titrimetric method where tea extract was titrated with standard potassium permanganate (KMnO4) solution according to the methods of AOAC (2016). During the determination of the tea tannins by titration, reagents i.e., gelatin solution, acidic $\mathrm{NaCl}$ solution and powdered kaolin were used. For the preparation of gelatin solution, $25 \mathrm{~g}$ of gelatin was soaked in saturated $\mathrm{NaCl}$ solution for $1 \mathrm{hr}$. The mixture was then heated until the gelatin became dissolved and allowed to cool down. Finally saturated $\mathrm{NaCl}$ was added and the solution was made up to $1 \mathrm{~L}$. Acidic $\mathrm{NaCl}$ solution were prepared by measuring $25 \mathrm{~mL}$ of concentrated H2SO4 in a 1L volumetric flask. Then $975 \mathrm{~mL}$ of saturated $\mathrm{NaCl}$ was added up to the graduation mark of the flask.

Oxidimetric titration of tea extract were done by following procedures. Firstly, $5 \mathrm{~mL}$ of tea extract was measured into a $500 \mathrm{~mL}$ conical flask. Then $12.5 \mathrm{ml}$ of indigo-carmine solution and $375 \mathrm{ml}$ of deionized distilled water were added into the conical flask. Then $\mathrm{KMnO} 4$ was used for titration with the mixture which was prepared previously. The KMnO4 was added until the blue color of the mixture changes into final yellow with a faint pink tint at the rim. At the endpoint, the volume of $\mathrm{KMnO} 4$ was recorded. This volume (' $\mathrm{Y}$ ' $\mathrm{mL}$ ) was required to titrate all the tannins and non-tannin compounds present in that tea extract. The amount of $\mathrm{KMnO} 4$ required to titrate the non-tannin compounds was ' $\mathrm{X}$ mL'. To determine the volume ' $\mathrm{X} \mathrm{mL}$ ', another $50 \mathrm{~mL}$ of tea extract was measured and added to the mixture of $25 \mathrm{~mL}$ gelatin solution, $50 \mathrm{ml}$ of the acidic $\mathrm{NaCl}$ solution and $5 \mathrm{~g}$ powdered kaolin. Next, the mixture was shaken followed by the filtration using Whatman no. 1 filter paper. From the filtrate around $12.5 \mathrm{~mL}$ was mixed with $12.5 \mathrm{~mL}$ of indigo-carmine solution and $375 \mathrm{~mL}$ of distilled deionized water. The whole mixture was titrated against the $\mathrm{KMnO} 4$ solution like the previous procedure until the color at the endpoint turned into faint pink. Finally, the real volume of $\mathrm{KMnO} 4$ required in the titration of tea tannin was evaluated from the difference between the value of $\mathrm{Y}$ and $\mathrm{X}$.

$1 \mathrm{ml}$ of standard $\mathrm{KMnO} 4$ solution $=0.595 \mathrm{ml}$ of $0.1 \mathrm{~N}$ Oxalic acid

$1 \mathrm{ml}$ of $0.1 \mathrm{~N}$ Oxalic acid $=0.0042 \mathrm{~g}$ of tannin

\section{Antioxidant activity determination}

Antioxidant capacity of the tea extracts was determined using DPPH assay as the method described by Azlim Almey et al. (2010) with slight modifications. $6 \mathrm{mg}$ of DPPH was dissolved in $100 \mathrm{~mL}$ methanol to prepare Methanolic DPPH solution. An aliquot $(0.5 \mathrm{~mL})$ of methanolic solution of extract containing different concentrations of $0.10,0.20,0.30,0.40$, 0.60 , and $0.80 \mathrm{mg} / \mathrm{mL}$ were added to $2.5 \mathrm{~mL}$ of methanolic DPPH solution. The mixture was gently shaken and left for $30 \mathrm{~min}$ in dark at room temperature. The absorbance was read at wavelength $517 \mathrm{~nm}$ using UV-VIS spectrophotometer (UV-2600, Shimadzu Corporation, USA). Control prepared by mixing $1 \mathrm{~mL}$ of methanol with $2 \mathrm{~mL}$ of DPPH solution while methanol was used as a blank. The scavenging activity was measured as the decrease in absorbance of the samples in comparison with the DPPH standard solution. Antioxidant capacity based on the DPPH free radical scavenging ability of extracts calculated using the following equation:

$$
\% \text { inhibition=1-Absorbance of sample/Absorbance of control } \times 100 \%
$$




\section{Statistical analysis}

The obtained data were stored in Microsoft Excel 2013 and then all statistical analysis were performed using R Statistical Software (version 3.4.1; R Foundation for Statistical Computing, Vienna, Austria).

\section{Results and discussion}

\section{Sensory evaluation}

The ranking of the tea samples obtained by evaluating the sensory data is developed instant black tea) $>$ commercial instant tea $>$ commercial black tea. Similar observations were made by Sinija and Mishra (2008); Someswararao and Srivastav (2012) for sensory evaluation of tea. All the quality attributes for instant tea and tea granules were rated from like extremely to moderately.

\section{Sensory evaluation of analyzed tea samples}

Table 1

\begin{tabular}{|c|c|c|c|c|c|c|}
\hline \multicolumn{2}{|c|}{ Tea Samples } & \multicolumn{5}{c|}{ The degree of liking/hedonic scale score (1-9) } \\
\hline Kinds of Tea & Sample & Color & Flavor & Pungency & Strength & Mouthfeel \\
\hline $\begin{array}{c}\text { Developed } \\
\text { Instant Black } \\
\text { Tea }\end{array}$ & $\mathrm{A}$ & 8.8 & 8.7 & 7.6 & 8.1 & 8.6 \\
\hline \multirow{3}{*}{$\begin{array}{c}\text { Commercial } \\
\text { Instant Tea }\end{array}$} & & & & & & \\
\cline { 2 - 7 } & $\mathrm{B}$ & 8.6 & 8.2 & 8.3 & 7.8 & 8.4 \\
\cline { 2 - 7 } & $\mathrm{D}$ & 7.2 & 7.4 & 6.8 & 7.9 & 7.8 \\
\cline { 2 - 7 } & $\mathrm{E}$ & 8.9 & 7.2 & 6.9 & 8.0 & 7.9 \\
\cline { 2 - 7 } Commercial & $\mathrm{F}$ & 8.4 & 8.4 & 7.1 & 7.8 & 7.8 \\
\cline { 2 - 7 } Black Tea & $\mathrm{G}$ & 8.5 & 7.9 & 8.1 & 7.7 & 7.5 \\
\cline { 2 - 7 } & $\mathrm{H}$ & 7.8 & 8.1 & 8.0 & 8.1 & 8.9 \\
\cline { 2 - 7 } & $\mathrm{I}$ & 8.4 & 8.4 & 8.2 & 8.3 & 8.1 \\
\cline { 2 - 7 } & $\mathrm{J}$ & 7.9 & 8.3 & 7.8 & 7.6 & 7.4 \\
\hline
\end{tabular}

Overall scale used: $9=$ like extremely; $8=$ like very much; $7=$ like moderately; $6=$ like slightly; $5=$ neither like nor dislike; $4=$ dislike slightly; $3=$ dislike moderately; $2=$ dislike very much; $1=$ dislike extremely.

\section{$\%$ Extractives of Tea}

Percentage of Extractives in tea samples determined are reported in Table 2. As Percentage of Extractives is an indicator for black tea granules, in this study only commercial black tea samples were analyzed and values were within $11.29 \%$ to $38.62 \%$. Some values were less than the legal limit of Bangladesh Standards and Testing Institution (BSTI) (30\%) that could be the indication of spent tea leaves, i.e., those that have been infused, dried and re-used (Hosen et al., 2014). 


\section{Caffeine}

The amount of caffeine in different tea samples tested was in the range between $2.2 \%$ to $3.1 \%(\mathrm{~g} / 100 \mathrm{~g}$ materials). The order of caffeine concentration in tea samples types was found as follows: Commercial Black Tea Granules $>$ Commercial Instant Tea $>$ Developed Instant Black Tea. Results obtained were higher than caffeine (\%) reported by Rabiul Islam et al. (2013) and similar to data reported by Rahman et al. (2012) and Hosen et al. (2014). The quantitative differences obtained among different kinds of tea is probably due to the method of processing of each kind since caffeine sublimes without decomposition upon exposure to heat, therefore it should be expected that caffeine could be lost during fermentation and processing. Also, the differences of caffeine quantity and consequently the percentage may be due to the different time of harvesting of leaves of the plant.

The caffeine content in standard black tea brew varies between 60 and $115 \mathrm{mg}$ per cup and in a cup of instant tea is $40 \mathrm{mg}$ caffeine content of developed instant black tea was found $2.2 \%$. This showed that the efficiency of conversion of caffeine during processing increases after extracting a part of the juice. Thus, it is seen that the instant tea produced by this method are comparable to that of standard black tea in major chemical constituents. Caffeine the major component of tea and regarded as a stimulant; excess of it can cause impairment of the mechanical properties of growing bone in early life (Oh et al., 2004).

Table 2

\% Extractives, Caffeine, Tannin, Total polyphenol content of analyzed tea samples

\begin{tabular}{|c|c|c|c|c|c|}
\hline \multicolumn{2}{|c|}{ Tea Samples } & \multirow{2}{*}{$\begin{array}{c}\text { Extractives } \\
(\%)\end{array}$} & \multirow{2}{*}{$\begin{array}{c}\text { Caffeine } \\
(\%)\end{array}$} & \multirow{2}{*}{$\begin{array}{c}\text { Total } \\
\text { Polyphenol }(\%)\end{array}$} & \multirow{2}{*}{$\begin{array}{c}\text { Tannin } \\
(\mathbf{\%})\end{array}$} \\
\hline Kinds of Tea & Sample & & & & \\
\hline $\begin{array}{c}\text { Developed Instant } \\
\text { Black Tea }\end{array}$ & $\mathrm{A}$ & - & $2.2 \%$ & $22.67 \%$ & $7.42 \%$ \\
\hline \multirow{3}{*}{$\begin{array}{c}\text { Commercial Instant } \\
\text { Tea }\end{array}$} & $\mathrm{B}$ & - & $2.4 \%$ & $17.45 \%$ & $8.56 \%$ \\
\hline & $\mathrm{C}$ & - & $2.5 \%$ & $17.96 \%$ & $8.49 \%$ \\
\hline & $\mathrm{D}$ & - & $2.8 \%$ & $17.38 \%$ & $8.03 \%$ \\
\hline \multirow{6}{*}{$\begin{array}{c}\text { Commercial Black } \\
\text { Tea }\end{array}$} & $\mathrm{E}$ & $27.41 \%$ & $3.1 \%$ & $18.01 \%$ & $9.8 \%$ \\
\hline & $\mathrm{F}$ & $21.74 \%$ & $2.6 \%$ & $19.67 \%$ & $9.01 \%$ \\
\hline & $\mathrm{G}$ & $14.58 \%$ & $2.9 \%$ & $18.71 \%$ & $9.72 \%$ \\
\hline & $\mathrm{H}$ & $38.62 \%$ & $3.1 \%$ & $22.56 \%$ & $10.28 \%$ \\
\hline & $\mathrm{I}$ & $11.29 \%$ & $2.6 \%$ & $18.71 \%$ & $9.89 \%$ \\
\hline & $\mathrm{J}$ & $34.61 \%$ & $3.0 \%$ & $21.72 \%$ & $10.43 \%$ \\
\hline
\end{tabular}

Results are means \pm standard deviation of triplicates

\section{Total polyphenols content}

Total polyphenols of analyzed tea samples were ranged between $17.38 \%$ and $22.67 \%$. Kerio et al. (2013) found total polyphenols in processed teas from the purple leaf colored cultivars ranged from $17.1 \%$ to $21.1 \%$ for aerated, is similar to the recent study. The results higher than findings of Rahman et al. (2012) who found the polyphenol content of $11.23 \%$ to $14.85 \%$ in various teas and coincidence with the finding $(19.33 \%)$ of Bharadwaz and Bhattacharjee (2012). Lin et al. (2003) reported that tea leaves contain high phenolic components which account for $25-35 \%$ on the dry weight basis. Soluble polyphenols 


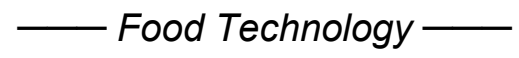

constitute about $15 \%$ of black tea but this variation may occur due to the different variety of tea, its geographical origin, environmental conditions and agronomic situations. As the contents of polyphenol found in this study were high in comparison to Lin et al. (2003) this may be due to the fact of oxidation of flavanols, flavandiols and theogallin during the conversion of fresh leaf to processed tea. In this study, developed instant black tea was found to have higher polyphenols as compared to others (Table 1). Besides, no significant variation was found between the polyphenol content of commercial instant tea samples because of their homogenous nature in comparison with other varieties $(\mathrm{p}>0.05)$. In this analysis, Commercial black tea samples show significant variation in polyphenol content which is higher than all.

Tea polyphenols have been reported to have strong antioxidant property and free radical scavenging activity due to possession of a phenolic hydroxyl group attached to the flavan-3ol structure. Free radicals are generated constantly due to the metabolism of food ingredients, physical stress, and oxidative stress mediated by various environmental pollutants/chemicals/toxins, radiation etc. These free radicals are implicated in numerous disorders in human such as cancer, angina pectoris, neurodegenerative diseases and atherosclerosis (Lobo et al., 2010). As the developed instant black tea has higher polyphenols than others it will have a beneficial effect against these diseases.

\section{Tannin content}

Results of tannin content in different samples of tea have been presented in Table 1. It was found that samples of commercial black tea had higher tannin content than commercial instant tea and developed instant tea. Tannin content in black tea ranged from 9.01 to $10.43 \%$. Highest tannin content in the studied was found in sample J. Developed instant black tea had the lowest tannin content of $7.42 \%$. Results were similar to the study of Ushir et al. (2011) 7.99 to $9.82 \%$ and lower to the reported value of Khasnabis et al. (2015) 11.76 to $15.14 \%$. Differences in tannin contents of different tea samples may be due to the difference in the process of manufacture, aging of tea leaves or the differences in climate and soil texture. Tea tannin, different from tannic acid, is a type of polyphenol present in tea leaves. Kaur et al. (2015) estimated the total polyphenolic content of 10 samples of black tea and 6 samples of green tea. They found that the total polyphenol content in green tea $(3.066 \pm 1.911 \mathrm{mg} \mathrm{TAE} / \mathrm{g})$ was significantly higher than in black tea $(0.72 \pm 0.55 \mathrm{mg} \mathrm{TAE} / \mathrm{g})(\mathrm{p}<0.05)$. The higher levels of polyphenols in green tea than black tea could be due to the conversion of the tea polyphenols into thearubigins and theaflavin during the fermentation process.

Tannins have traditionally been considered anti-nutritional but it is now known that their beneficial or anti-nutritional properties depend upon their chemical structure and dosage. If ingested in excessive quantities, tannins inhibit the absorption of minerals, such as iron which may, if prolonged, lead to anemia (Dommgang et al., 1998). As developed instant black tea has low tannin content $(7.42 \%)$ as compared to other black tea, consequences of such antinutritional factors will be minimized.

\section{Antioxidant activity}

Antioxidant activity, measured by the DPPH method, was expressed as inhibition percentage. Inhibition of the free radical DPPH was measured and data are presented in Figure 2. Developed instant black tea (A) showed the highest potency of scavenging activity on DPPH radical followed by commercial instant green tea and black tea granules. No significant difference in potency value was observed for commercial black tea granules (E, 


\section{— Food Technology -}

F, G, H, I and J) as evident from Figure 2. When further investigated, significant differences $(p<0.05)$ in DPPH inhibition were observed between commercial instant green and black tea samples.

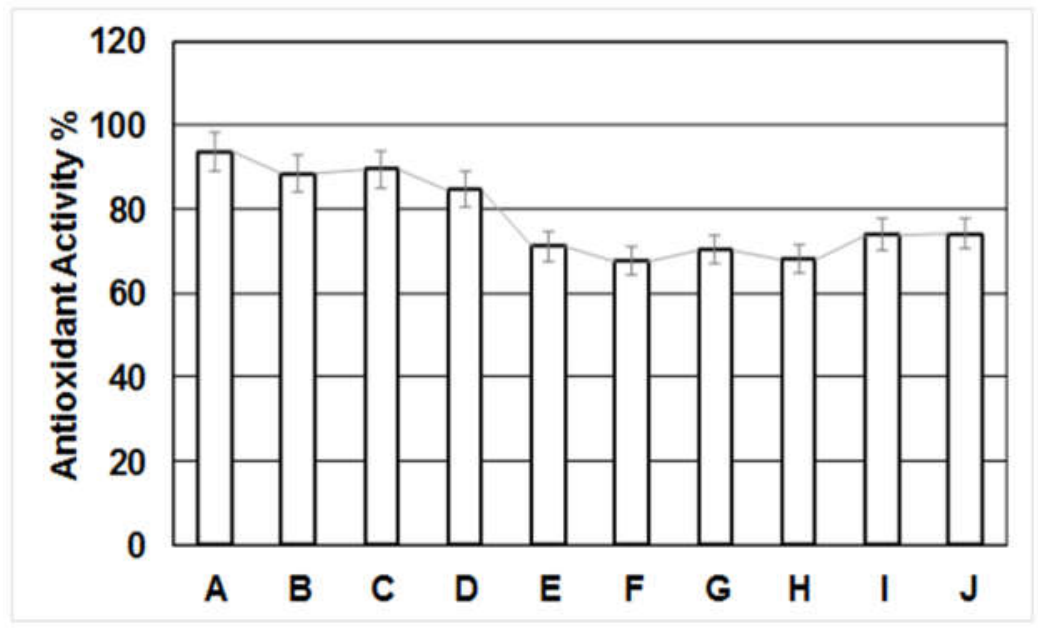

Figure 2. Antioxidant activity (\% inhibition) of analyzed tea samples

A - Developed Instant Black Tea;

B, C, D - Commercial instant tea brand;

E, F, G, H, I, J - Commercial black tea granule brands.

Antioxidant activities of commercial instant green tea are higher than green tea from USA (70.1\%), Sri Lanka (55.0), China (60\%) and Japan (68\%) (Rababah et al., 2004; Armoskaite et al., 2011) and the values are closely related to (\%) antioxidant activity of Indian green tea $(92.84 \%)$ (Sandip et al., 2012). Antioxidant activity of green tea brand of South Africa (90.8\%) was higher than that reported for in the present study for Bangladesh green tea brand (Gadow et al., 1997). Black tea brand (81.7\%) from South Africa, however, is reported to have much higher antioxidant activity than Bangladesh black tea brands tested. However, all instant green tea showed higher antioxidant activity than commercial black tea granules (Figure 2). The antioxidant activity and reducing power of the tested tea samples showed high correlation with the polyphenol content.

\section{Conclusion}

A novel technique for the production of antioxidant-rich instant tea has been established in this investigation. The instant tea produced by this method is of good color, pungency and other liquoring characteristics and soluble even in cold water.

Caffeine, tannin and polyphenol contents are also in the acceptable range.

The findings of the present study indicate that developed instant tea will be a good source of plant polyphenols which may possess antioxidant, anti-inflammatory and cancerpreventive action. 


\section{- Food Technology -}

The low content of caffeine allows its use by pregnant women, children, and people with cardiovascular diseases and anxiety disorders as a stimulant beverage with proven health properties.

\section{References}

1. AOAC (2016), Official Methods of Analysis. 20th Edition, Association of Official Analytical Chemists, Washington, DC., 30, pp. 10-11.

2. Armoskaite V, Ramanuskiene K, Maruska A, Razukas A, Dagilyte A, Baranauskas A, Briedis V. (2011), The analysis of quality and antioxidant activity of green tea extracts, Journal of Medicinal Plants Research, 5(5), pp. 811-816.

3. Atomssa, T. and Gholap, A.V. (2011), Characterization of caffeine and determination of caffeine in tea leaves using uv-visible spectrometer, African Journal of Pure and Applied Chemistry, 5(1), pp. 1-8.

4. Azlim Almey, A.A., Ahmed Jalal Khan, C., Syed Zahir, I., Mustapha Suleiman, K., Aisyah, M.R. and Kamarul Rahim, K. (2010), Total phenolic content and primary antioxidant activity of methanolic and ethanolic extracts of aromatic plants' leaves, International Food Research Journal, 17(4), pp. 1077-1084.

5. Bharadwaz, A. and Bhattacharjee, C. (2012), Extraction of polyphenols from dried tea leaves, International Journal of Scientific \& Engineering Research, 3(5), pp. 1-6.

6. Carr M.K.V. (1972), Stephens, W. Climate, Weather and the Yield of Tea. In: Tea: Cultivation to Consumption; Willson, K. C., Clifford, M. N., Eds.; Chapman \& Hall, pp. London, pp 87-135.

7. Carr, M.K.V. (1972), The climatic requirements of the tea plant: A review, Experimental Agriculture, 8(1), pp. 1-14.

8. Chung, K.T., Wong, T.Y., Wei, C.I., Huang, Y.W. and Lin, Y. (1998), Tannins and human health: a review, Critical reviews in food science and nutrition, 38(6), pp. 21-464.

9. Dommgang, F., Eka, O.U. and Fokou, H. (1998), Nutrient composition of some leafy vegetable eaten in Cameroun (1): Evaluation of sugars, crude fat, mineral and oxalic acid, Nigerian Journal of Nutritional Sciences, 19, pp. 97-104.

10. Dufresne, C.J. and Farnworth, E.R. (2001), A review of latest research findings on the health promotion properties of tea, The Journal of nutritional biochemistry, 12(7), pp. 404-421.

11. Gadow A, Joubert E, and Hansmann C.F. (1997), Comparison of the antioxidant activity of rooibos tea (Aspalathus linearis) with green, oolong and black tea, Food Chemistry, 60(1), pp. 73-77.

12. Graham, H. N. (1999). Tea, In: Wiley Encyclopedia of Food Science and Technology, 2nd ed.; Frederick, J. F., Ed.; John Wiley \& Sons, pp. New York, Vol. 1-4, pp. 2292-2305.

13. Hampp, A., (1996), The extraction of caffeine from tea, pp. A modification of the procedure of Murray and Hansen, Journal of chemical education, 73(12), pp. 1172.

14. Hosen, M., Karmokar, N., Bhuiyan, M., Khanam, J. and Rahman, M. (2014), Estimation of Caffeine, Niacin and Calorie Content in Tea Commonly Consumed by Dhaka City Residents, Indian Journal of Pharmaceutical and Biological Research, 2(4), pp. 84-88.

15. Iwasa, K. Sakamoto, Y. and Torii, H. (1966), Improvement of official chemical analysis of tea. II. Examination of water extract determination, Study of Tea, 33, pp 69-71. 
16. Kaur, A., Kaur, M., Kaur, P., Kaur, H., Kaur, S. and Kaur, K. (2015), Estimation and comparison of total phenolic and total antioxidants in green tea and black tea, GJBB International Journal of Science and Nature, 4(1), pp. 116-20.

17. Kerio, L.C., Wachira, F.N., Wanyoko, J.K. and Rotich, M.K. (2013), Total polyphenols, catechin profiles and antioxidant activity of tea products from purple leaf coloured tea cultivars, Food chemistry, 136(3-4), pp. 1405-1413.

18. Khasnabis, J., Rai, C. and Roy, A. (2015), Determination of tannin content by titrimetric method from different types of tea, Journal of Chemical and Pharmaceutical Research, 7(6), pp. 238-241.

19. Komes, D., Horzic, D., Belscak, A., Kovacevic Ganic, K. and Bljak, A. (2009), Determination of caffeine content in tea and maté tea by using different methods, Czech Journal of Food Science, 27, pp. 213-216.

20. Lin, Y.L., Juan, I.M., Chen, Y.L., Liang, Y.C. and Lin, J.K. (1996), Composition of polyphenols in fresh tea leaves and associations of their oxygen-radical-absorbing capacity with antiproliferative actions in fibroblast cells, Journal of Agricultural and Food Chemistry, 44(6), pp. 1387-1394.

21. Lobo, V., Patil, A., Phatak, A. and Chandra, N. (2010), Free radicals, antioxidants and functional foods, pp. Impact on human health, Pharmacognosy reviews, 4(8), p.118.

22. Luczaj, W. and Skrzydlewska, E. (2005), Antioxidative properties of black tea review article, Preventive Medicine, 40(6), pp. 910-918.

23. Manley (1965), Extractives from tea. Journal of the American Pharmaceutical Association, 3, 101, In: Manuals of food quality control, 8 Food analysis: quality, adulteration and test of identity, FAO Food and Nutrition Papers 14/8. 1986, Rome, p. 316.

24. Miean, K.H. and Mohamed, S. (2001), Flavonoid (myricetin, quercetin, kaempferol, luteolin, and apigenin) content of edible tropical plants, Journal of agricultural and food chemistry, 49(6), pp. 3106-3112.

25. Mohammed, M.I. and Sulaiman, M.A. (2009), Proximate, caffeine and tannin analyses in some brands of tea consumed in Kano Metropolis, Nigeria, Bayero Journal of Pure and Applied Sciences, 2(2), pp. 19-21.

26. Muktar, H.; Ahmad, N. (2000), Tea polyphenols, pp. prevention of cancer and optimizing health, American Journal of Clinical Nutrition, 71, pp. 1698-1702.

27. Muzolf, M. and Tyrakowska, B. (2007), Health benefits of green tea - a review, Polish Journal of Human Nutrition and Metabolism, 34(3/4), pp.1225-1229.

28. Oh, J.H., Kim, E.H., Kim, J.L., Kang, J.S., Moon, Y.I. and Kang, Y.H. (2004), Study on antioxidant potency of green tea by DPPH method, Journal of The Korean Society of Food Science and Nutrition, 33, pp. 1079-1084

29. Potter, N.W. (1968), Hedonic Scale: Food Science, The AVI Publishing Co, Connecticut, pp. $115-17$.

30. Rababah TM, Hettiarachchy NS, and Horax R. (2004), Total phenolics and antioxidant activities of fenugreek, green tea, black tea, grape seed, ginger, rosemary, gotu kola, and ginkgo extracts, vitamin E, and tertbutylhydroquinone, Journal of Agricultural and Food Chemistry, 52(16), pp.5183-5186.

31. Rabiul Islam, G.M., Gias Uddin, M., Mahfuzur Rahman, M. Yousuf, A. (2013), Caffeine and total polyphenol contents of market tea cultivated and processed in Bangladesh, Malaysian journal of nutrition, 19(1), pp.143-147.

32. Rahman, M.M., Kalam, M.A. and Islam, M.M. (2012), Change of chemical compositions in semi-fermented tea on land elevation, Tea Journal of Bangladesh, 41, pp. 11-16. 
33. Sandip, P., Debjani, G., Chabita, S., Chakrabarti, A.K., Datta, S.C. and Dey, S.K. (2012), Total polyphenol content, antioxidant activity and lipid peroxidation inhibition efficacy of branded tea (Camellia sinensis) available in India, International Journal of Tea Science (IJTS), 8(3), pp. 13-20.

34. Sinija, V.R. and Mishra, H.N. (2008), Fuzzy analysis of sensory data for quality evaluation of instant green tea powder and granules, Food and Bioprocess Technology, http, pp.//dx.doi.org/10.1007/s11947-008-0163.x.

35. Someswararao, C. and Srivastav, P.P. (2012), A novel technology for production of instant tea powder from the existing black tea manufacturing process, Innovative Food Science \& Emerging Technologies, 16, pp. 143-147.

36. South, P.K. and Miller, D.D. (1998), Iron binding by tannic acid: effects of selected ligands, Food Chemistry, 63(2), pp. 167-172.

37. Ushir, Y., Luha, A., Abhang, S. and Vadalia, K. (2011), Estimation of secondary metabolites in different tea and coffee brands from Indian market, International journal of pharmacy \& life sciences, 2(3), pp. 599-600.

38. Wang, H., Provan, G.J. and Helliwell, K. (2000), Tea flavonoids, pp. their functions, utilisation and analysis, Trends in Food Science \& Technology, 11(4-5), pp. 152-160.

39. Yang, C.S. (2002), Effects of tea consumption on nutrition and health, Journal of Nutrition, 132(12), pp. 2409-2412.

40. Yao, L.H., Jiang, Y.M., Caffin, N., D'arcy, B., Datta, N., Liu, X., Singanusong, R. and $\mathrm{Xu}$, Y. (2006), Phenolic compounds in tea from Australian supermarkets, Food Chemistry, 96(4), pp. 614-620. 